\title{
The Use of 3S Technology to Assess Cocoa Swollen Shoot Virus Disease in Offinso Cocoa District Area, Ghana
}

\author{
Fred Oduro Sarpong ${ }^{1, ~ *, ~ J o n a t h a n ~ A r t h u r ~ Q u a y e-B a l l a r d ², ~ E r n e s t ~ B i n e y ² ~}$ \\ ${ }^{1}$ Cocoa Health and Extension Division, Ghana Cocoa Board (COCOBOD), Kumasi, Ghana \\ ${ }^{2}$ Department of Geomatic Engineering, Kwame Nkrumah University of Science and Technology, Kumasi, Ghana
}

Email address:

freddyswanzy@gmail.com (F. O. Sarpong)

${ }^{*}$ Corresponding author

\section{To cite this article:}

Fred Oduro Sarpong, Jonathan Arthur Quaye-Ballard, Ernest Biney. The Use of 3S Technology to Assess Cocoa Swollen Shoot Virus Disease in Offinso Cocoa District Area, Ghana. Journal of Health and Environmental Research. Vol. 7, No. 4, 2021, pp. 169-180.

doi: $10.11648 /$ j.jher.20210704.11

Received: September 3, 2021; Accepted: September 26, 2021; Published: October 12, 2021

\begin{abstract}
The cocoa industry is ruined by Cocoa Swollen Shoot Virus Disease (CSSVD) caused by a virus transmitted by mealybugs. Initiatives by Ghana Cocoa Board to control the disease have not been all that successful over the years. The study aimed at exploring Geographic Information System (GIS), Remote Sensing (RS), and Global Position System (GPS) techniques to assess the prevalence of CSSVD in terms of their geographic locations by comparing the $2^{\text {nd }}$ and $3^{\text {rd }}$ Country Wide Surveys (CWS) undertaken by Cocoa Health and Extension Division (CHED) in the Offinso cocoa district of Ghana. Handheld GPS, GIS shapefiles, and Landsat 7 and 8 satellite images were used. Geo-spatial overlay operations of shapefiles and performances on NDVI computations yielded relationships between the $2^{\text {nd }}$ and $3^{\text {rd }}$ CWS on CSSVD farms over ten years period from 2009 to 2019. It was revealed that only 12.99 hectares of the disease are found in the $2^{\text {nd }} \mathrm{CWS}$ was persistent under the $3^{\text {rd }} \mathrm{CWS}$ and this was due to successful treatment of infected area during the $2{ }^{\text {nd }} \mathrm{CWS}$. Also, the health of cocoa under the $3^{\text {rd }} \mathrm{CWS}$ had improved to 262.89 hectares from the previously infected 275.89 hectares. Thus, treatment of the CSSVD was effective and the vegetative health index of the farms emanated from the treatment was also encouraging. The results show the impact on the control of CSSVD for the sustainable production of cocoa. In addition, the research method serves as a guideline for other related studies in an attempt to investigate, quantify and project CSSVD.
\end{abstract}

Keywords: Cocoa, 3S Technology, CSSVD, NDVI, Country Wide Surveys

\section{Introduction}

One of the major issues affecting cocoa production is the Cocoa Swollen Shoot Virus Disease (CSSVD) caused by a virus transmitted by a mealybug which was first identified in Ghana in the year 1936 [1]. It is undoubtedly the single most significant menace to the Ghanaian cocoa sector [2]. The disease spreads from tree to tree by several species of mealybugs (Pseudococcidae) and is known to be the most destructive plagues of cocoa that in the 1940s threatened to wipe out the cocoa industry in Ghana [3]. Despite the huge economic benefits derived from cocoa, the industry continues to be ruined by the CSSVD menace which has no cure apart from cutting down the trees which are infected with the virus and their contacts. This official treatment campaign in Ghana has seen the removal of over 200 million trees since 1946 [4, 5]. In an attempt to curb the disease, the Cocoa Health and Extension Division (CHED) of the Ghana Cocoa Board has the mandate to ensure that all cocoa trees in the country are incident-free from all forms of diseases especially CSSVD [6]. CHED has over the years tried to curtail the cocoa diseases by putting in place measures to ensure that every single cocoa tree is healthy some of which include CSSVD Control through periodic country wide survey of all cocoa growing areas and the Cocoa Diseases and Pest Control (CODAPEC) also known as the cocoa mass spraying as well as farmer education on good agronomic practices through Community Extension Agents [6]. Treatment of the disease infected farms identified 
during the surveys is presently key and largely most effective way of treatment among other methods. This initiative is known to be costly and labour intensive though [7]. First and second country wide surveys have been completed and the third is in the offing to be completed soon.

Different approaches and initiatives have been employed by researchers to studying the disease and controlling it but the problem still pervades [4]. However, what has not been considered is to keenly study and compare the Country Wide Surveys (CWS) done by CHED to acquaint with the modern trend of the canker. Although removal of the trees affected by the disease and their contacts have been carried out for many years in the country, the spread of the Swollen Shoot Virus (SSV) continues to manifest [1]. Thus, the need to research the activities of CHED by comparing $2^{\text {nd }}$ and $3^{\text {rd }}$ CWS. The research seeks to use $3 \mathrm{~S}$ (Geographic Information System (GIS), Remote Sensing (RS), and Global Position System (GPS)) Technology to assess the spatial distribution of CSSVD in the $2^{\text {nd }}$ and $3^{\text {rd }}$ Country Wide Surveys (CWS) undertaken by CHED in the Offinso cocoa district. 3S (GIS, RS, and GPS) Technology is gaining importance in ecological monitoring, natural resource, and environmental management [8-12]. RS technology makes it easy to obtain homogeneous data [13], covering the entire study area over the period of the third country wide survey to know the current status of the previously treated farms through the performance of Normalize Difference Vegetative Index (NDVI). The application of $3 \mathrm{~S}$ technology will reveal the drift of the disease and therefore direct Ghana Cocoa Board (COCOBOD) management as to how to control the menace to increase cocoa production. This will inevitably bring the required socio-economic development in Ghana since the economy of the country thrives on cocoa [2]. The rate at which the disease is spreading and its related problems or implications are very disturbing [1] and if not dealt with in this manner will jeopardize the cocoa industry.

The above calls for the study of the research where the application will readily and easily assess the prevalence of the disease in terms of their geographic locations by comparing the two CWS done by CHED in the Offinso cocoa district. That is, to examine the spatial relationship of the disease between the two surveys using $3 \mathrm{~S}$ technology where composite maps will be derived for Cartographic Visualization. The derived maps make it possible to identify the prevailing status of farms that were treated of the disease under the second countrywide survey.

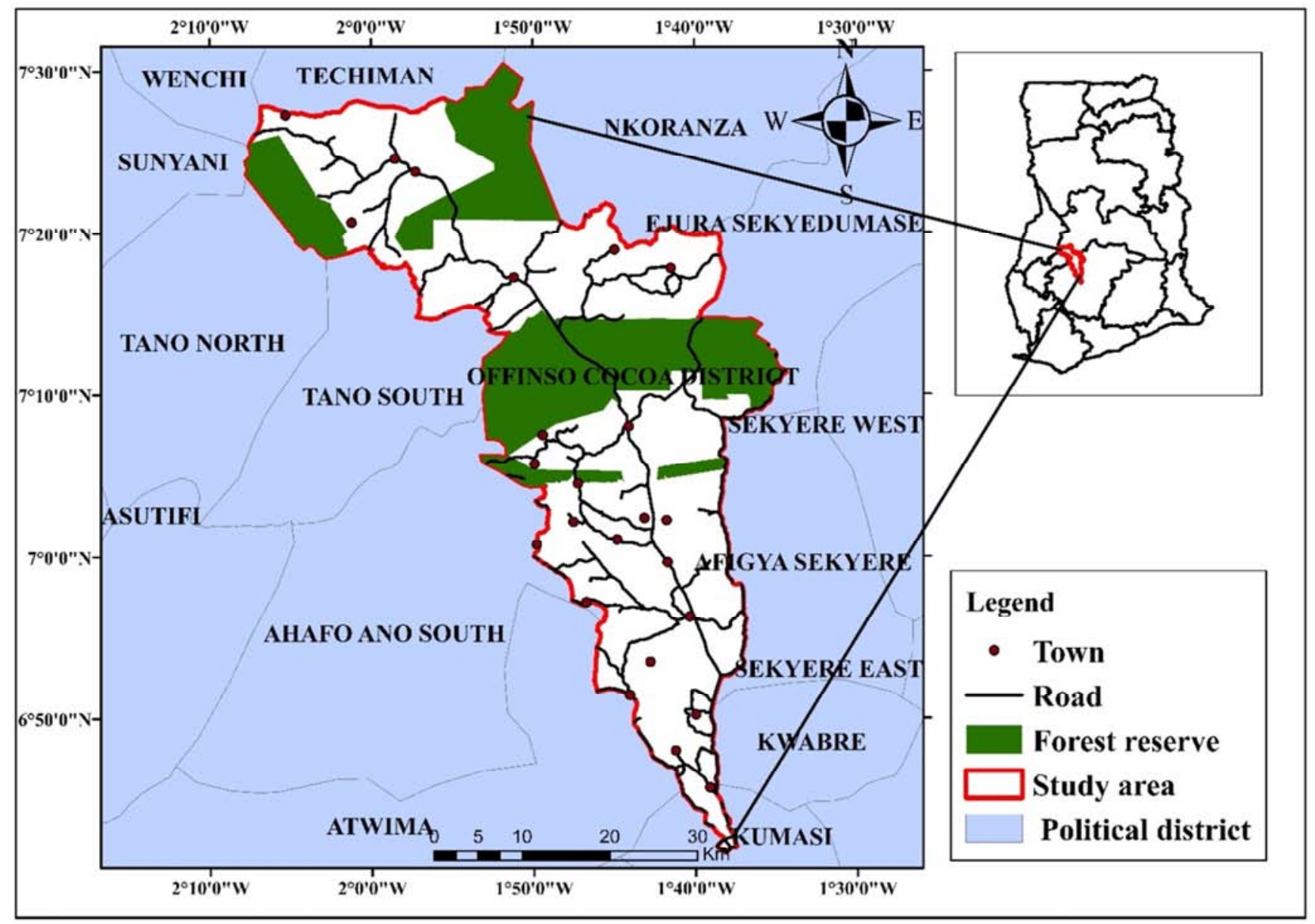

Figure 1. Map of the study area. 


\section{Materials and Methods}

\subsection{Study Area}

The study area (Figure 1) is carved from two political districts namely Offinso municipal and Offinso-North which lies between longitude $1^{\circ} 38^{\prime} \mathrm{W}-2^{\circ} 8^{\prime} \mathrm{W}$ and latitude $6^{\circ} 52^{\prime} \mathrm{N}-7^{\circ} 30^{\prime} \mathrm{N}$ approximately as shown in figure 1 . The area is bounded to the north by Techiman municipal and Nkoranza south, to the south by Atwima Nwabiagy, to the east by Ejura Sekyere Dumase and Afigya Kwabre and to the west by Sunyani West, Tano North, Tano South, and Ahafo Ano South districts. These two districts together have a population of 133,776 out of which 65,368 are male and 68,408 females. Offinso municipal and Offinso North district respectively cover an approximate total landmass of $585.7 \mathrm{~km}^{2}$ and $945.9 \mathrm{~km}^{2}$ [14]. Offinso municipal has a mean annual rainfall of $953.4 \mathrm{~mm}$ with temperatures ranging between $21^{\circ} \mathrm{C}$ and $32^{\circ} \mathrm{C}$ whereas the municipal is characterized by two main rainy seasons. The main rain season is between May and August whiles the minor one is between September and November followed by the harmattan season which prevails till February. Offinso-North district also experiences a mean annual rainfall ranging between $700 \mathrm{~mm}$ and $1200 \mathrm{~mm}$ with a minimum temperature of $30^{\circ} \mathrm{C}$ between March and April. The vegetation cover of both districts is mostly semi-deciduous forest with a considerable large amount of Guinea Savannah vegetation in parts of Offinso North District. The study area has a total of six forest reserves namely Afram Headwaters, Opro, Afransu-Brohoma, Asuofu East, Asuofu West, and Mankrang Forest Reserve $[15,16]$. The main occupation in the study area is farming and to the large extent mostly cocoa farming. The farming activities are predominantly rainfed.

\subsection{Data, Equipment, and Procedures}

Several datasets (Table 1) were obtained for use in this study. These datasets were collected from various sources, both local and global, and prepared properly to allow for proper analysis and correct results. The Juno 3D Handheld GPS equipment and GIS software were used. The datasets used are outlined in Table 1.

Table 1. Dataset used.

\begin{tabular}{lll}
\hline S/N & Data/Format & Source/ Year/Spatial Resolution \\
\hline 1 & Political district boundaries of Ghana (ESRI Shapefile) & The Survey Division of the Lands Commission of Ghana, 1:50,000 \\
2 & Landsat 7 and 8 (Geotiff) & USGS (Dec. 2009 to Dec 2015 and Dec 2019), 30m \\
3 & CSSVD Infested Areas of 2 ${ }^{\text {nd }}$ and 3 ${ }^{\text {rd }}$ CWS (ESRI Shapefile) & CHED Offinso District (Dec. 2009 to Dec 2015 and Dec 2019 +/- 3m \\
4 & GPS Measurement (ESRI Shapefile) & CHED Offinso District Field survey (Dec. 2019), +/- 3m \\
\hline
\end{tabular}

To obtain the general pictorial distribution of the disease outbreaks in the two surveys, their respective shapefiles were mapped in the GIS software. The 2nd CWS commenced in 2009 and ended in 2015. The $3^{\text {rd }} \mathrm{CWS}$ which commenced in 2017 was still ongoing at the time of the study. It was, therefore, appropriate to compare only the surveyed areas with their counterparts of the same geographic locations under the $2^{\text {nd }} \mathrm{CWS}$. The overlay tools under the analysis tool of the GIS software were used to examine the spatial relationship between the CSSVD farms of the two countrywide surveys and analyzed under the following categories.

For newly emerged CSSVD after the 3rd CWS, the geographical areas that hitherto did not have the disease in the 2nd CWS but were found to have had the disease in the third countrywide survey which was mapped and analyzed. Hence the Erase Tool in the GIS overlay package was used. For the treated or lost after the 2nd CWS, the Erase Tool was used again to map and analyze those geographical areas that the disease was found to have existed during the $2^{\text {nd }} \mathrm{CWS}$ but in the $3^{\text {rd }}$ CWS it was no longer found using shapefile of $2 \mathrm{rd}$ CWS. For the CSSVD found Common to both 2nd and 3rd CWSs, the CSSVD Disease farms found common to both 2 nd CWS and 3rd CWS were analyzed using the Intersect Tool. This overlay tool computes a geometric intersection of the input features. These areas otherwise known as Areas of Persistence Outbreak were computed for further analysis. To readily visualize and give a clear pictorial description of the treated farms as geographically located in the study area, the GIS software was used to map the treated farms of the second countrywide survey. Shapefiles of the treated farms from the second countrywide survey of the study area as well as the shapefile of the boundary of the study area from CHED were updated with their respective attribute information. The output shapefiles resulting from all the overlay operations discussed were projected from WGS 1984 spatial reference system to WGS 1984 UTM Zone 30N coordinate for area calculations. The spatial relationship between the infected areas of $2^{\text {nd }}$ and $3^{\text {rd }}$ CWS was mapped and visualized in GIS software and the findings were analyzed.

\subsection{Raster Data Processing and NDVI Computation}

The Landsat datasets were taken through preprocessing in GIS software to remove errors and to prepare the images for analysis. NDVI, a graphical indicator used to analyze RS data and assess the "greenness" of the area under scrutiny was used to assess the status of replanted cocoa farms by measuring the differences between the Near-Infrared Band (NIR, which is reflected strongly by vegetation) and the red band (which is absorbed easily by vegetation). NDVI ranges from +1 (maximum likelihood of dense/healthy vegetation) to -1 (dead or no vegetation). The NDVI formula [17] is given by:

$$
N D V I=(N I R-R E D) /(N I R+R E D)
$$

where NIR and RED are the reflectances in the Near Infrared 
and red bands respectively. Thus, based on equation (1) the Red and NIR bands for Landsat 7 and 8 images were loaded into the GIS Raster calculator and used to calculate and obtain the NDVI for the various periods.

\subsection{Geo-statistical Analysis}

Zonal statistics was then carried out to extract NDVI values and determine the change in NDVI over time for each of the farms under observation. Zonal statistics tool under the Spatial Analyst toolbox of GIS software summarizes the values of a raster within the zones of another dataset and reports the results to a table. In determining the health status of the treated farms for each year of study, NDVI values for preceding years when the farms had not been treated were compared to the NDVI values of 2019. Therefore, each of these yearly averages for the seven years was subtracted from their corresponding 2019 NDVI averages. This was done to find whether the health status of the farms in terms of their NDVI values had appreciated or otherwise after treatment. Each of the changes or differences represented the average NDVI value of the farm understudy for a particular year. These differences in the averages between the past and corresponding 2019 NDVI values for all the years were computed and used as indicators of change in the Vegetative Health Index for the years in question. Temporal average NDVI patterns of treated farms were then generated from the survey using Microsoft Excel.

\section{Results and Discussion}

\subsection{Relationship Between CSSVD Farms of the $2^{\text {nd }}$ and $3^{\text {rd }}$ Countrywide Surveys}

One hundred and ten $2^{\text {nd }}$ CWS CSSVD outbreaks sparsely distributed across the study area measured 275.98 hectares whiles the $3^{\text {rd }} \mathrm{CWS}$ had thirty-one of the disease which also measured 71.87 hectares as shown in Table 2. Their spatial distribution is as shown in Figures 2 and 3.

Table 2. Details of CSSVD used in the relationship.

\begin{tabular}{lll}
\hline Survey & Count of CSSVD & Area (Hectares) \\
\hline $2^{\text {nd }} \mathrm{CWS}$ & 110 & 275.89 \\
$3^{\text {rd }} \mathrm{CWS}$ & 31 & 71.865 \\
\hline
\end{tabular}

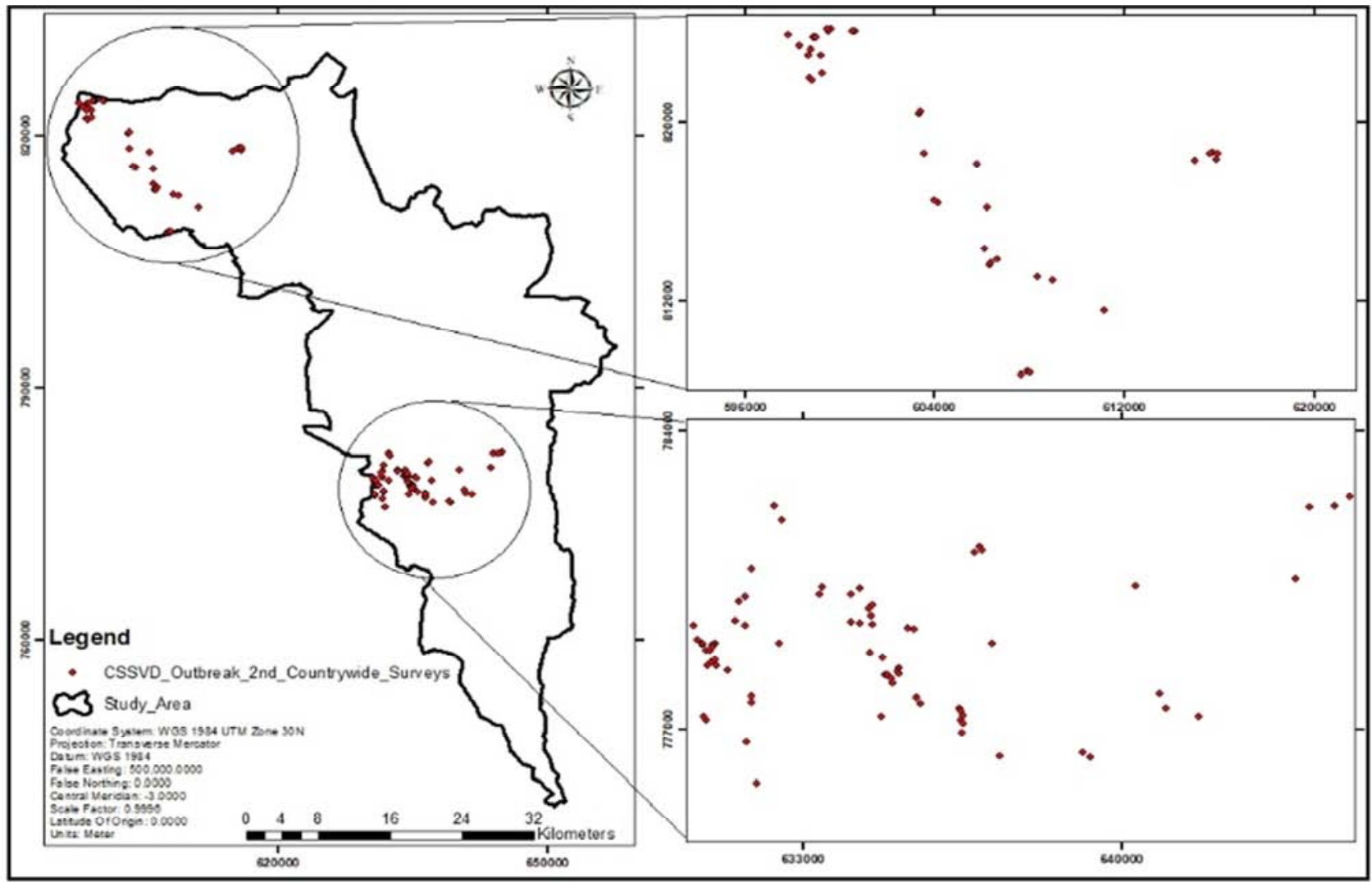

Figure 2. Spatial distribution of CSSVD under $2^{\text {nd }} C W S$. 


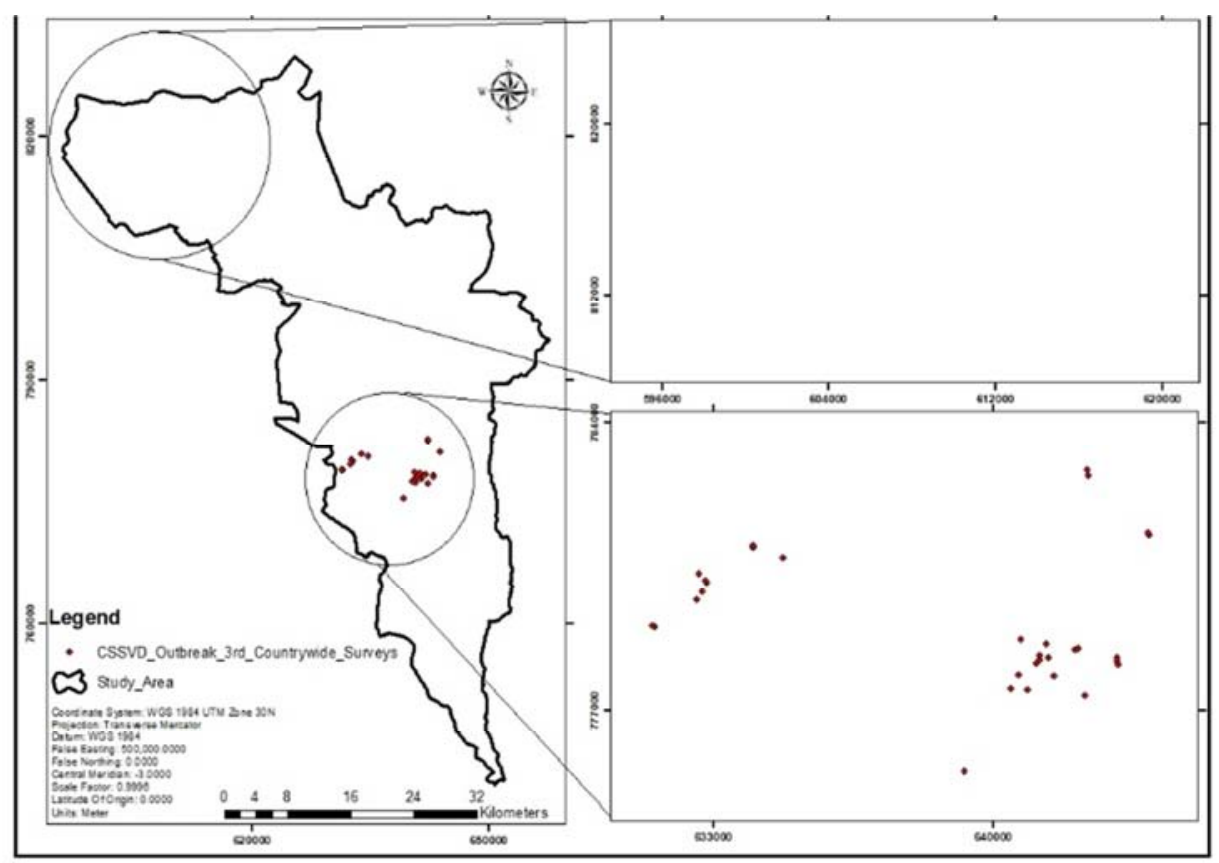

Figure 3. Spatial distribution of CSSVD under $3^{\text {rd }}$ CWS.

Generally, visualizing Figure 2 and Figure 3, it was found that no area of the northern section of the study area that had undergone $3^{\text {rd }}$ CWS had CSSVD infection as seen in the $2^{\text {nd }}$ CWS. However, portions of the southern section that had undergone $3^{\text {rd }}$ CWS had some significant CSSVD infection found as recorded in the $2^{\text {nd }}$ CWS. This implies that the disease control in the northern section had improved since areas surveyed so far in the $3^{\text {rd }} \mathrm{CWS}$ had no incidence of the disease recorded as shown in Figure 3 as compared to the prevalence of the disease in the southern section.

\subsection{Areas of Persistence Outbreak}

From Table 2, it is established that only 12.99 hectares of disease area representing 4.71 percent of the disease are found in the $2^{\text {nd }} \mathrm{CWS}$ was persistent under the $3^{\text {rd }} \mathrm{CWS}$ as shown in Figure 4. It could be inferred that treatment of the disease during the $2^{\text {nd }}$ CWS was generally successful since the infected area had dropped from 275.89 to 12.99 hectares. This persistence of the disease could be attributed to the fact that either the disease in this area was partially or not treated at all during the $2^{\text {nd }} \mathrm{CWS}$, or there was re-emergence of the disease due to poor treatment.

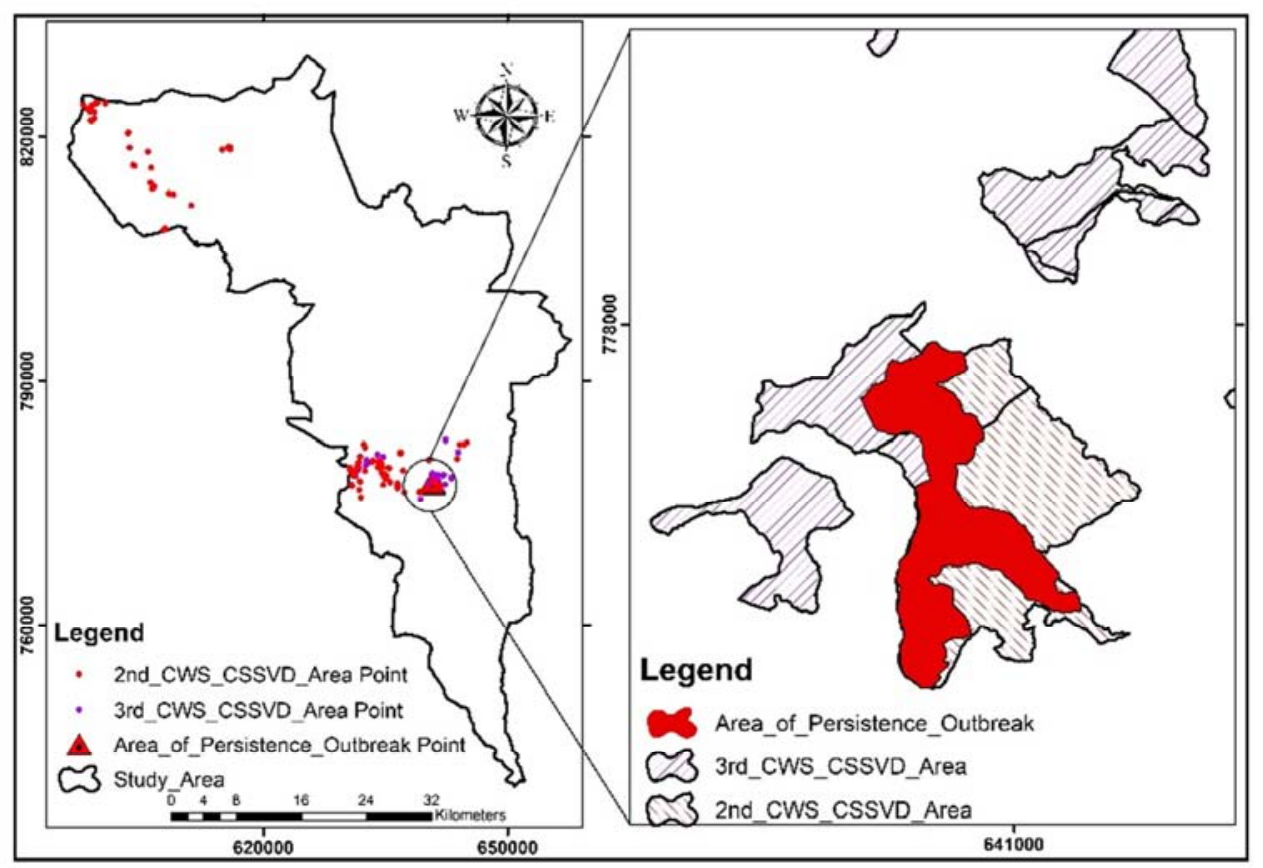

Figure 4. Areas of persistence outbreak. 


\subsection{Lost CSSVD Outbreak Areas}

Table 3 shows the areas of the $2^{\text {nd }}$ CWS CSSVD outbreaks found lost during the $3^{\text {rd }}$ CWS whiles Figure 5 shows their spatial distribution.

Table 3. Lost CSSVD outbreak areas.

\begin{tabular}{llll}
\hline Area & $\mathbf{2}^{\text {nd }} \mathbf{C W S ~ C S S V D ~ A r e a ~ ( H a ) ~}$ & CSSVD Area Lost (Ha) & Percentage Lost \\
\hline Northern Section & 82.67 & 82.67 & 100 \\
Southern Section & 193.22 & 180.22 & 93.27 \\
Total/Entire Area & 275.89 & 262.89 & 95.29 \\
\hline
\end{tabular}

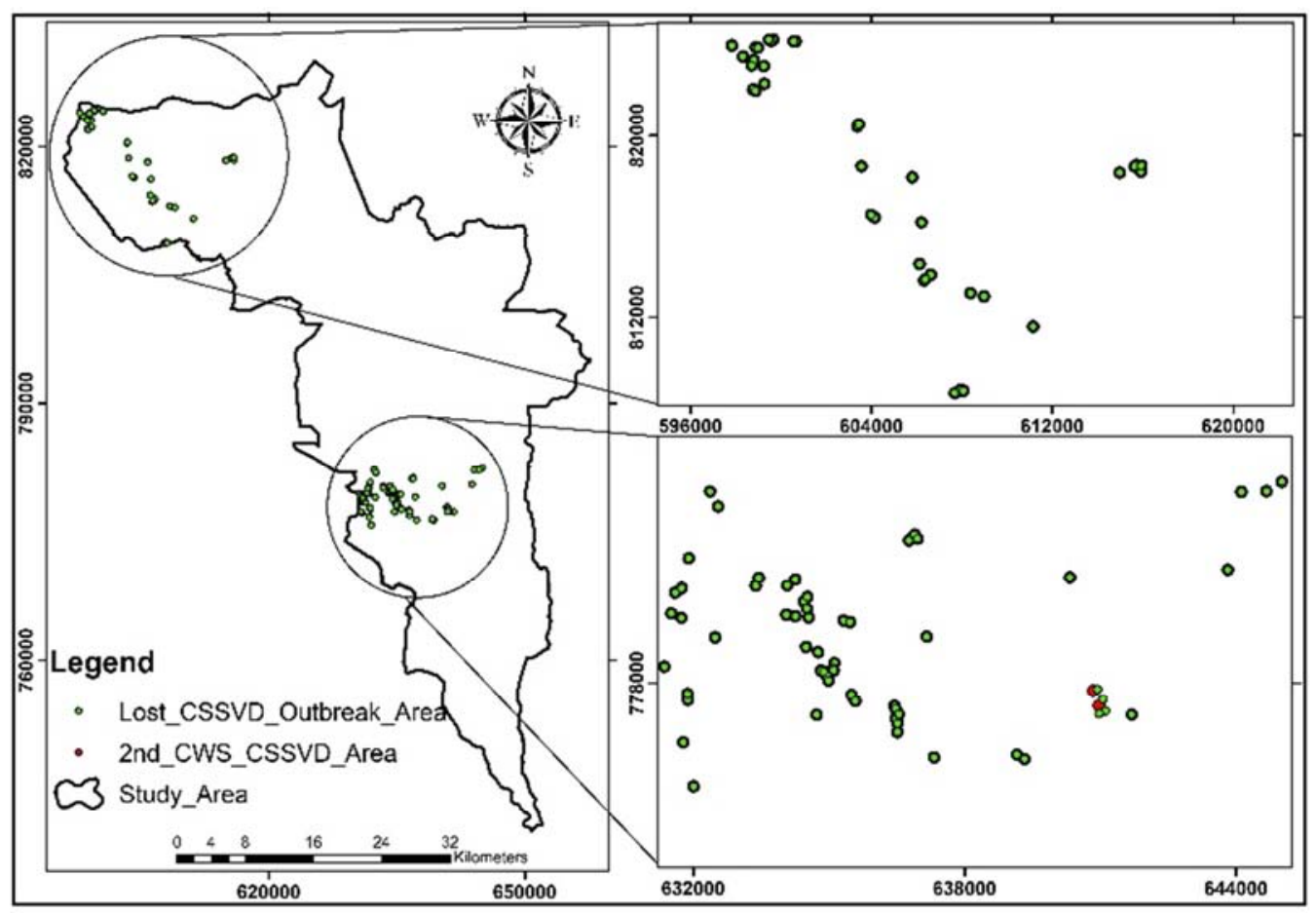

Figure 5. Areas of lost CSSVD under $3^{\text {rd }}$ CWS.

The results as shown in table 3 shows that 262.89 hectares which represent $95.29 \%$ of the disease captured in the $2^{\text {nd }}$ CWS $(275.89 \mathrm{Ha})$ disappeared during the $3^{\text {rd }} \mathrm{CWS}$. This is an indication that the treatment of the disease under the $2^{\text {nd }} \mathrm{CWS}$ in the entire study area was effective and could best be attributed to proper treatment practices employed. Also considering the northern and southern sections of the study area as mentioned earlier, there was a $100 \%$ loss of the disease in the northern section whiles the southern section lost $93.27 \%$. This also suggests that all factors contributing to the control of the disease were relatively better in the northern section as compared to the southern section of the study area as shown in Figure 6.

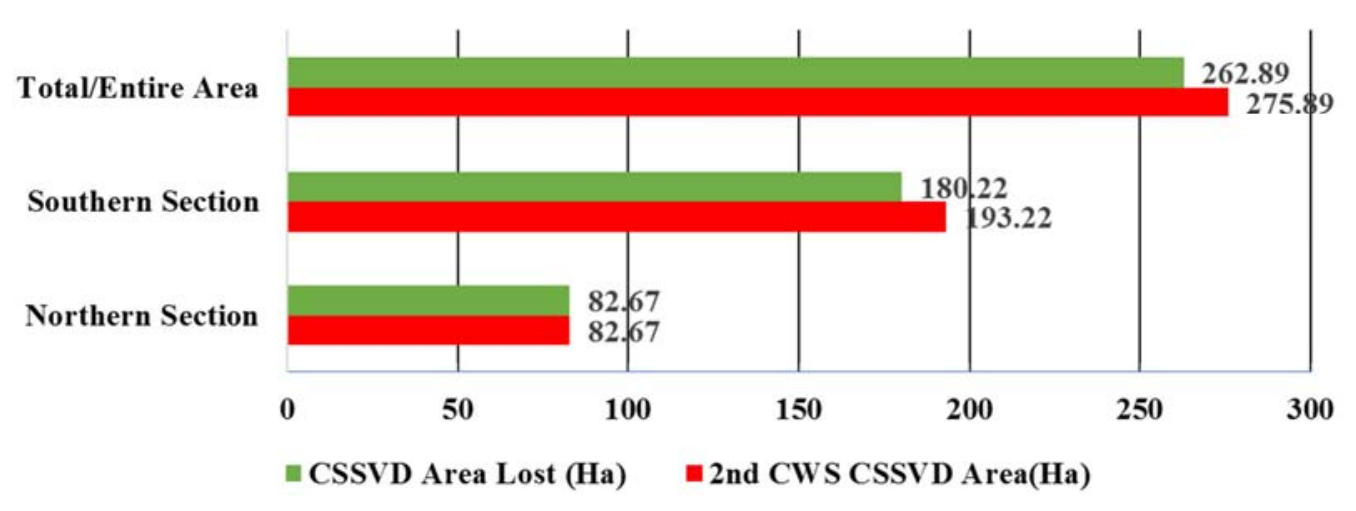

Figure 6. Relative CSSVD lost areas. 


\subsection{Newly Emerged CSSVD Areas}

Figure 7 shows areas that hitherto did not have the disease in the $2^{\text {nd }} \mathrm{CWS}$ but were found to have had the disease in the $3^{\text {rd }}$ CWS. It is worthy to note that all the newly emerged outbreaks were found in the southern section of the study area. These newly emerged CSSVD outbreaks in the $3^{\text {rd }}$ CWS had an area of 58.88 hectares compared to 275.89 hectares in the $2^{\text {nd }} \mathrm{CWS}$ representing $21.34 \%$ as shown in Table 4 and Figure
8. Generally, this shows a downward trend of the disease within the study area. The southern section's newly emerged disease areas measured $30.47 \%$ of what was recorded earlier in the $2^{\text {nd }}$ CWS within that region. This suggests that extra attention should be given to the control of the disease in the southern section as against the northern section which recorded no new incidence of the disease.

Table 4. Newly emerged CSSVD areas.

\begin{tabular}{llll}
\hline Area & $\mathbf{2}^{\text {nd }}$ CWS CSSVD Area (Ha) & $\mathbf{3}^{\text {rd }}$ CWS Newly Emerged CSSVD Area (Ha) & Percentage \\
\hline Northern Section & 82.67 & 0.00 & 0.00 \\
Southern Section & 193.22 & 58.88 & 30.47 \\
Total/Entire Area & 275.89 & 58.88 & 21.34 \\
\hline
\end{tabular}

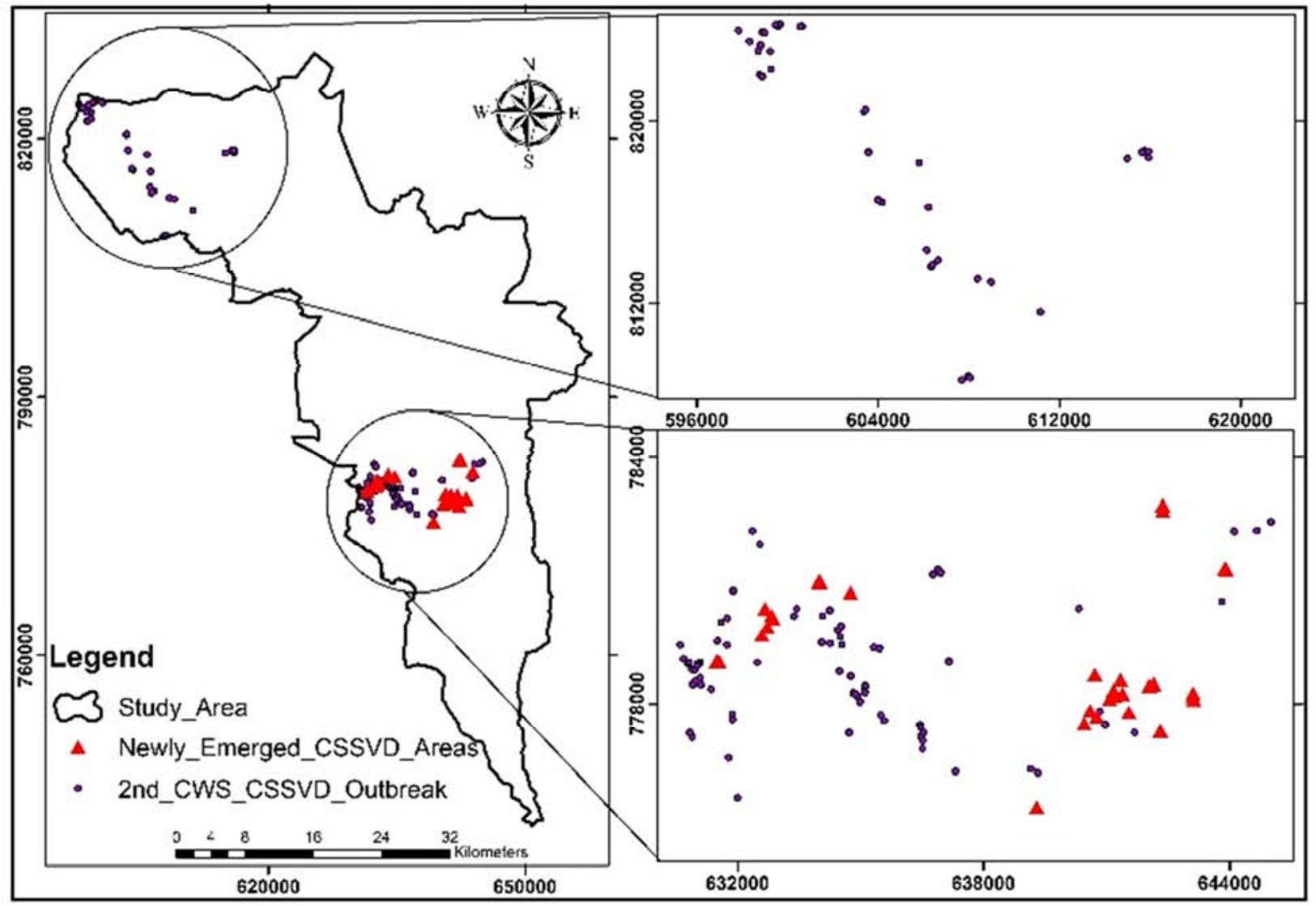

Figure 7. Relative location of newly emerged CSSVD outbreaks.

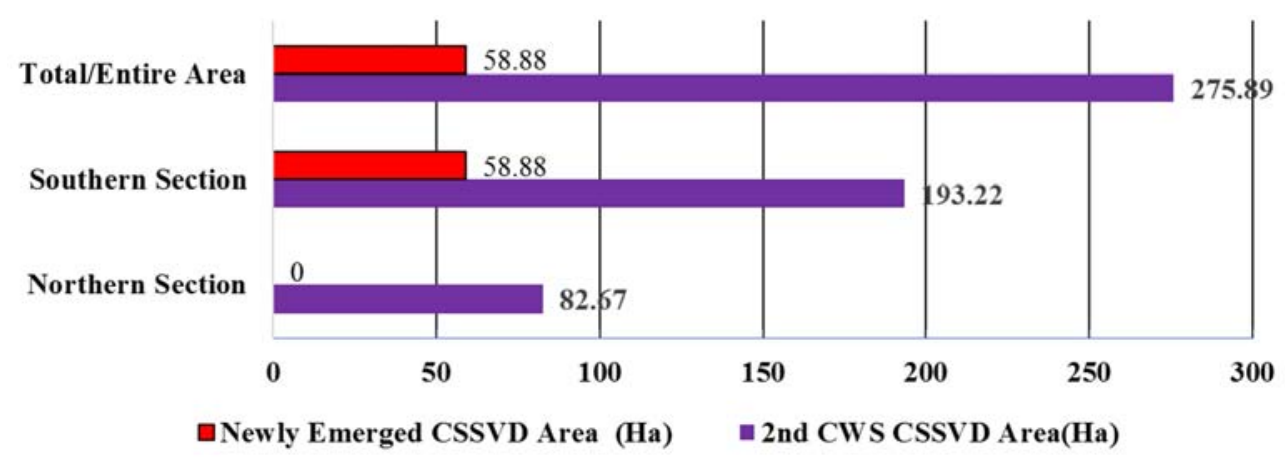

Figure 8. Newly emerged CSSVD outbreaks to $2^{\text {nd }}$ CWS outbreaks. 


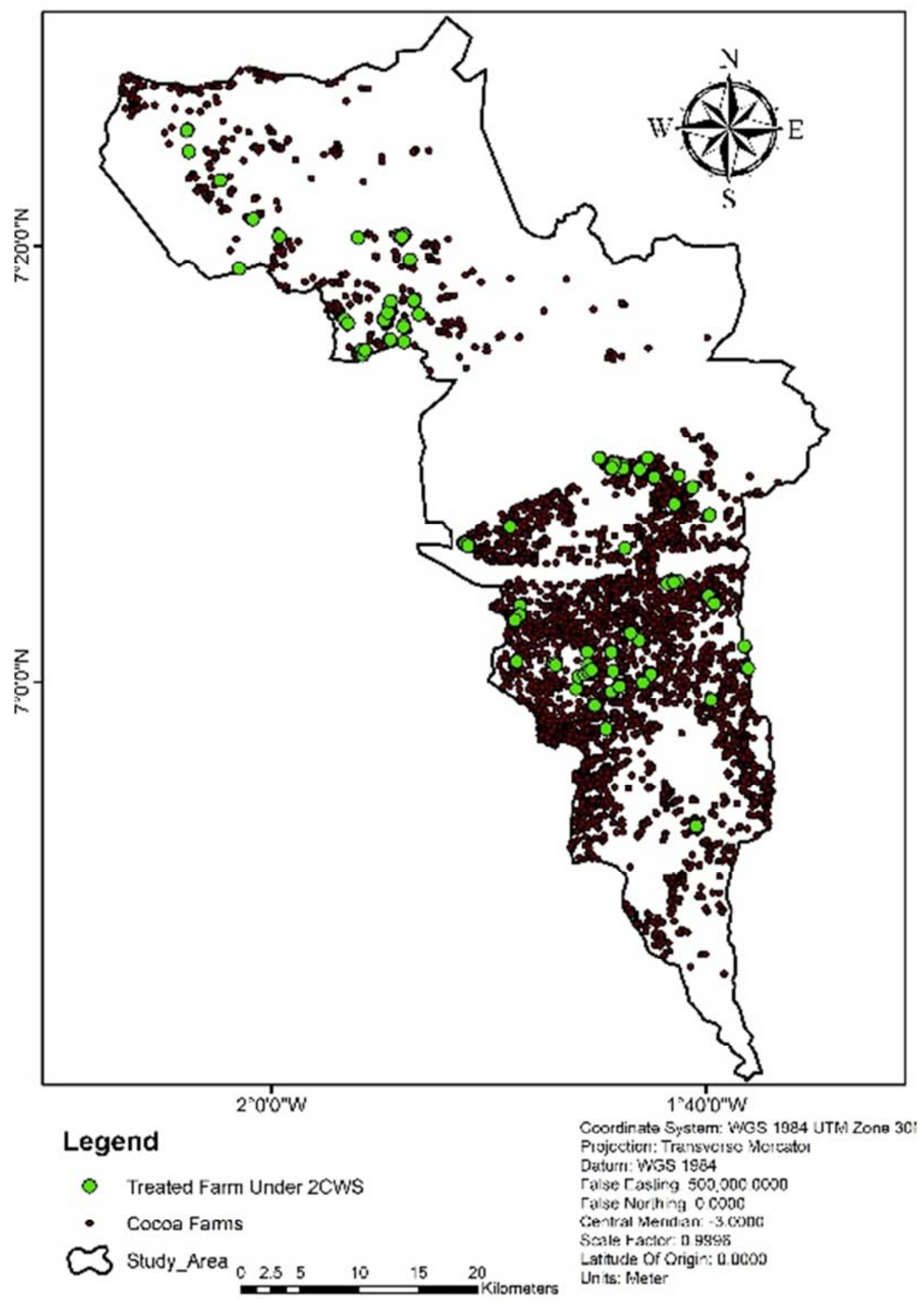

Figure 9. Distribution of treated farms in $2^{\text {nd }} \mathrm{CWS}$.

\subsection{Mapped Farms Treated of CSSVD in the Study Area Under the $2^{\text {nd }} \mathrm{CWS}$}

From Figure 9, it could be visualized that treatment of CSSVD has been done in both northern and southern sections of the study areas. A total of 106 farms covering 124.68 hectares of CSSVD outbreak Farms were treated and planted during the $2^{\text {nd }} \mathrm{CWS}$ representing 45.19 percent of the disease.

\subsection{Status of Farms Treated of CSSVD Under the $2^{\text {nd }}$ CWS}

The results of the NDVI computations, extraction, and statistics to determine the health status of farms treated with CSSVD under the $2^{\text {nd }} \mathrm{CWS}$ in terms of their NDVI values are as tabulated, visualized, and discussed below. Table 5 shows the averaged NDVI values for CSSVD farms in the year 2009 before treatment in the year 2010 as depicted in Figure 10 
whiles Table 6 and Figure 11 shows their respective NDVI map and values as of 2019. The differences between these two NDVI values of the same region and other years under study are as tabulated in Table 6. Some of the other NDVI maps generated are shown in figures 11 and 12 .

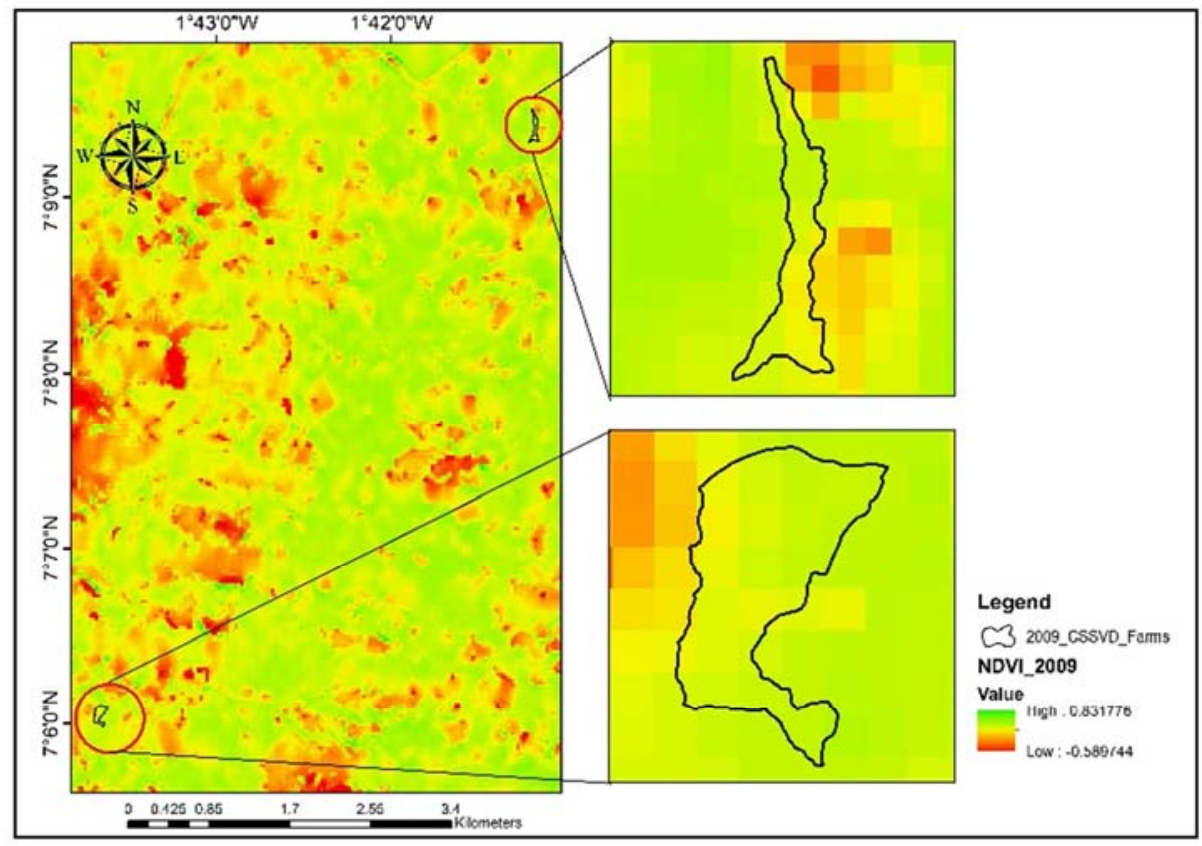

Figure 10. 2009 NDVI of some selected CSSVD farms before Treatment.

Table 5. NDVI calculations for 2009 treated farms.

\begin{tabular}{llllllll}
\hline Row ID & OBJECTID & COUNT & MIN & MAX & RANGE & MEAN & STD \\
\hline 1 & 9 & 17 & 0.322835 & 0.419355 & 0.09652 & 0.382192 & 0.027121 \\
2 & 13 & 8 & 0.398601 & 0.457143 & 0.058541 & 0.432248 & 0.018174 \\
3 & 22 & 16 & 0.305085 & 0.417323 & 0.112238 & 0.366345 & 0.040315 \\
4 & 46 & 13 & 0.314286 & 0.421875 & 0.107589 & 0.375053 & 0.027315 \\
$\sum$ & & & & & & 0.3889595 & \\
\hline
\end{tabular}

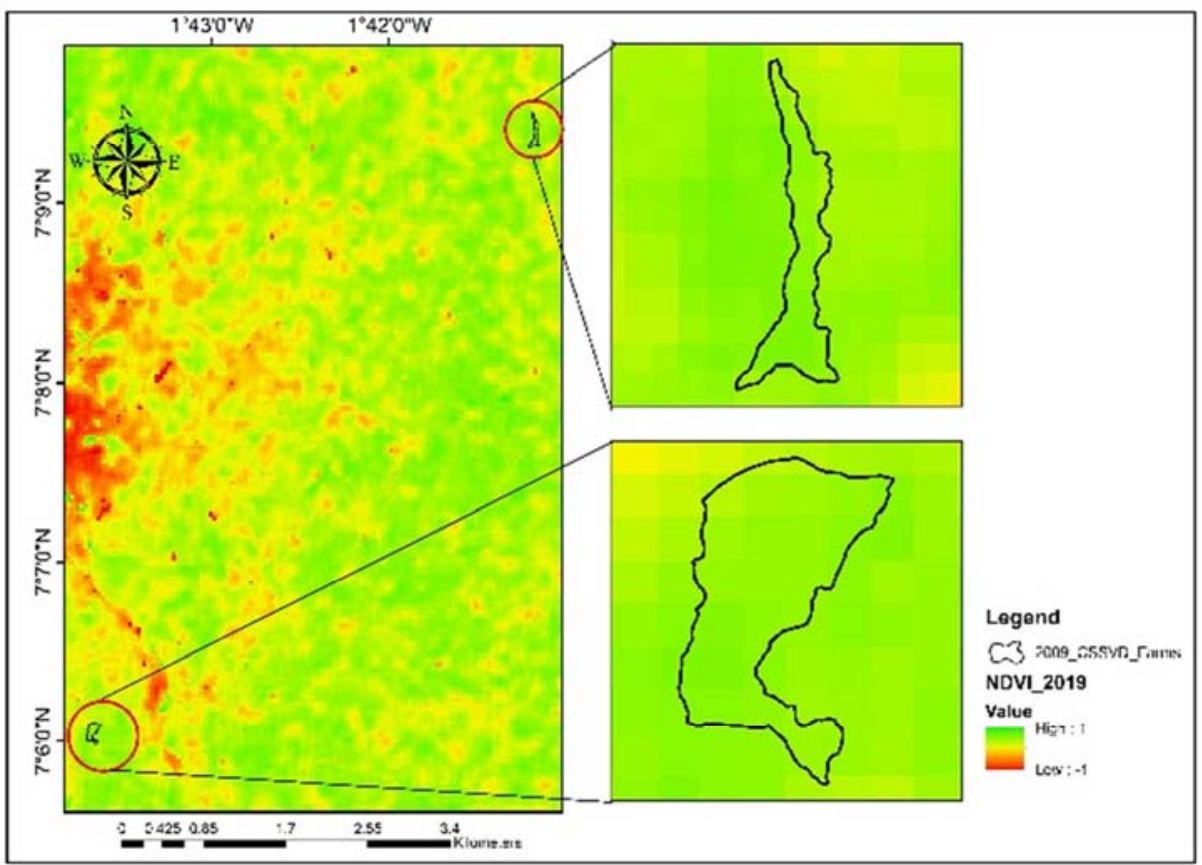

Figure 11. 2019 NDVI of the farms after treatment. 
Table 6. Corresponding NDVI calculations for 2019 farms.

\begin{tabular}{|c|c|c|c|c|c|c|c|}
\hline Row ID & OBJECTID & COUNT & MIN & MAX & RANGE & MEAN & STD \\
\hline 1 & 9 & 17 & 0.332372 & 0.378857 & 0.046485 & 0.359884 & 0.010532 \\
\hline 2 & 13 & 8 & 0.258931 & 0.313881 & 0.05495 & 0.284191 & 0.015545 \\
\hline 3 & 22 & 16 & 0.33806 & 0.381419 & 0.043359 & 0.365486 & 0.012558 \\
\hline 4 & 46 & 13 & 0.349884 & 0.375325 & 0.025441 & 0.361278 & 0.007169 \\
\hline$\sum$ & & & & & & 0.34271 & \\
\hline
\end{tabular}

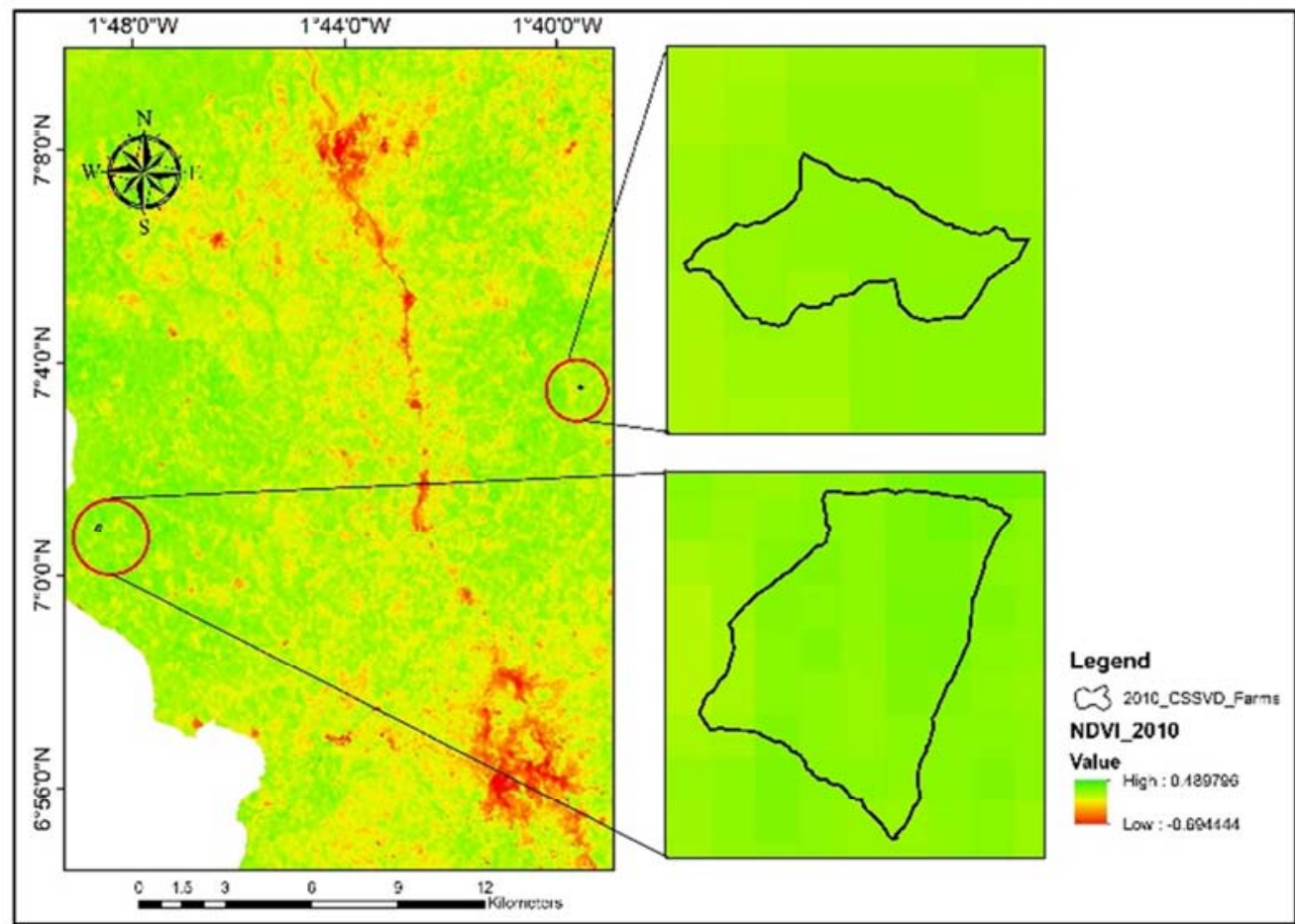

Figure 12. 2010 NDVI of some selected CSSVD farms before treatment.

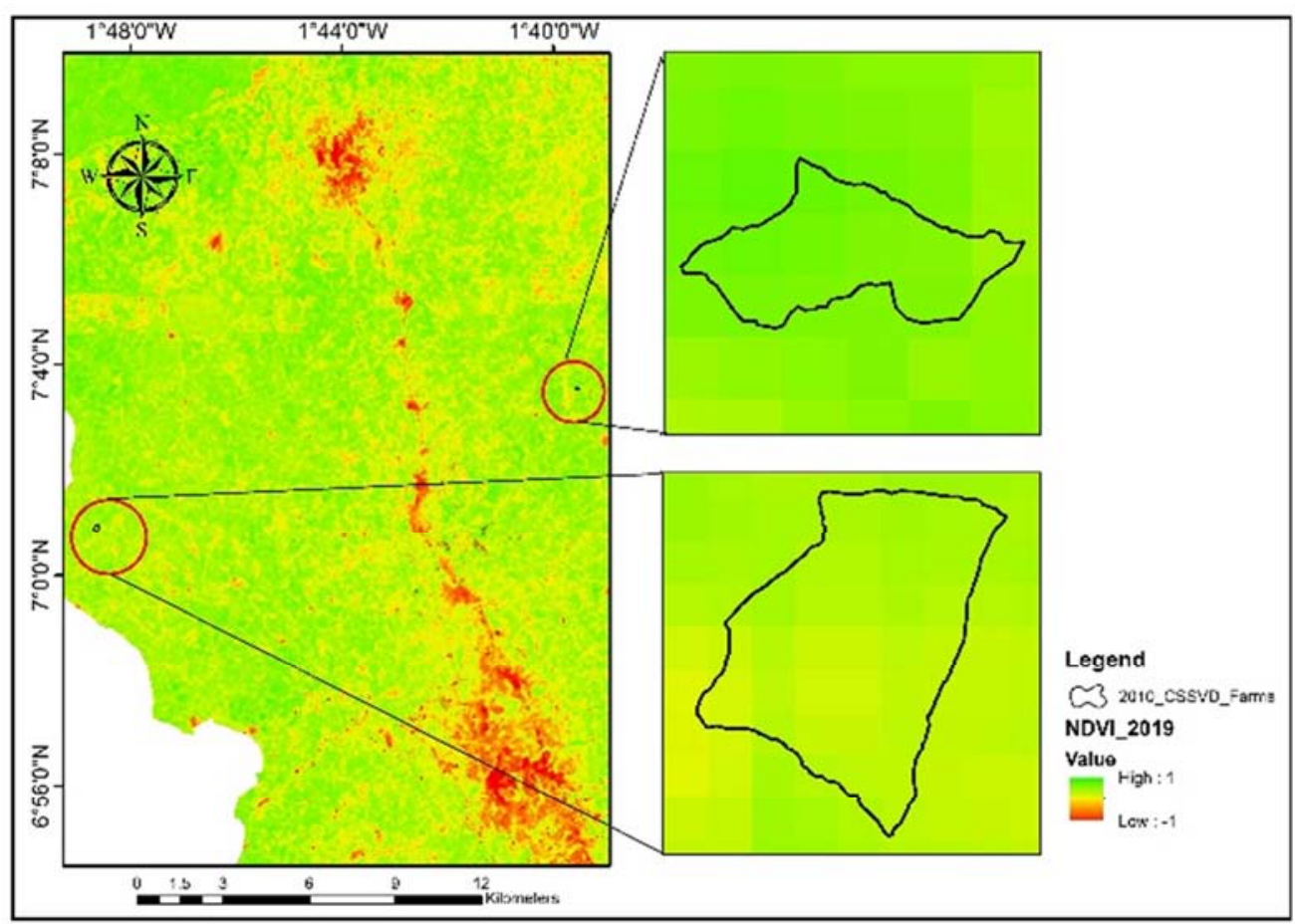

Figure 13. 2019 NDVI of some selected CSSVD farms after treatment. 
From Table 7 and Figure 14, it is observed that 2010, 2011, 2012, and 2015 farms treated with CSSVD disease had a positive change in terms of NDVI values of 0.23783 , $0.075044,0.032098$, and 0.043148 respectively with 2010 recording the highest $(0.23783)$. This shows that there has been a relative improvement in the health status of these farms. However, 2009, 2013, and 2014 showed a negative change of NDVI of $-0.04625,-0.04426$, and -0.44478 respectively out of which 2014 showed the worst change. This phenomenal fall in NDVI values of these farms could be attributed to several factors. [18], argued that since the year 2002 tests that were once effective for detection of CSSVD failed to detect the virus in $50-70 \%$ of symptomatic cocoa plants in Ghana and Cote d'Ivoire, suggesting the possible emergence of an uncharacterized CSSV variant. Base on this premise, it is possible that this category of farms mentioned above that had the signs of the disease per their outlook was indeed not
CSSVD infected. Instead of these farms losing their green leaves and getting withered after being discovered, flourished and blossomed thus misleading the control team. Furthermore, one can infer that these farms were not being taken proper care of after they had been treated hence their condition being worse off than before.

Notwithstanding the above category of farms which had relatively low NDVI computations, all other year periods registered a significant positive value in 2019, values far higher than their counterpart figures before treatment. Given the above considerations of the NDVI values in respect of the project years, it can be deduced that the status of the treated farms observed in 2019 was relatively better than it used to be before their treatments. CSSVD treatment within the study period had been generally successful since the status of four out of the seven years showed positive changes.

Table 7. Differences in NDVI for selected time periods.

\begin{tabular}{llllllll}
\hline Time Period & $\mathbf{2 0 0 9}$ & $\mathbf{2 0 1 0}$ & $\mathbf{2 0 1 1}$ & $\mathbf{2 0 1 2}$ & $\mathbf{2 0 1 3}$ & $\mathbf{2 0 1 4}$ & $\mathbf{2 0 1 5}$ \\
\hline NDVI Before Treatment & 0.38896 & 0.101353 & 0.243486 & 0.310366 & 0.380326 & 0.367645 & 0.288554 \\
NDVI @ 2019 & 0.34271 & 0.339183 & 0.31853 & 0.342465 & 0.336067 & -0.07713 & 0.331702 \\
Difference & -0.04625 & 0.23783 & 0.075044 & 0.032098 & -0.04426 & -0.44478 & 0.043148 \\
\hline
\end{tabular}

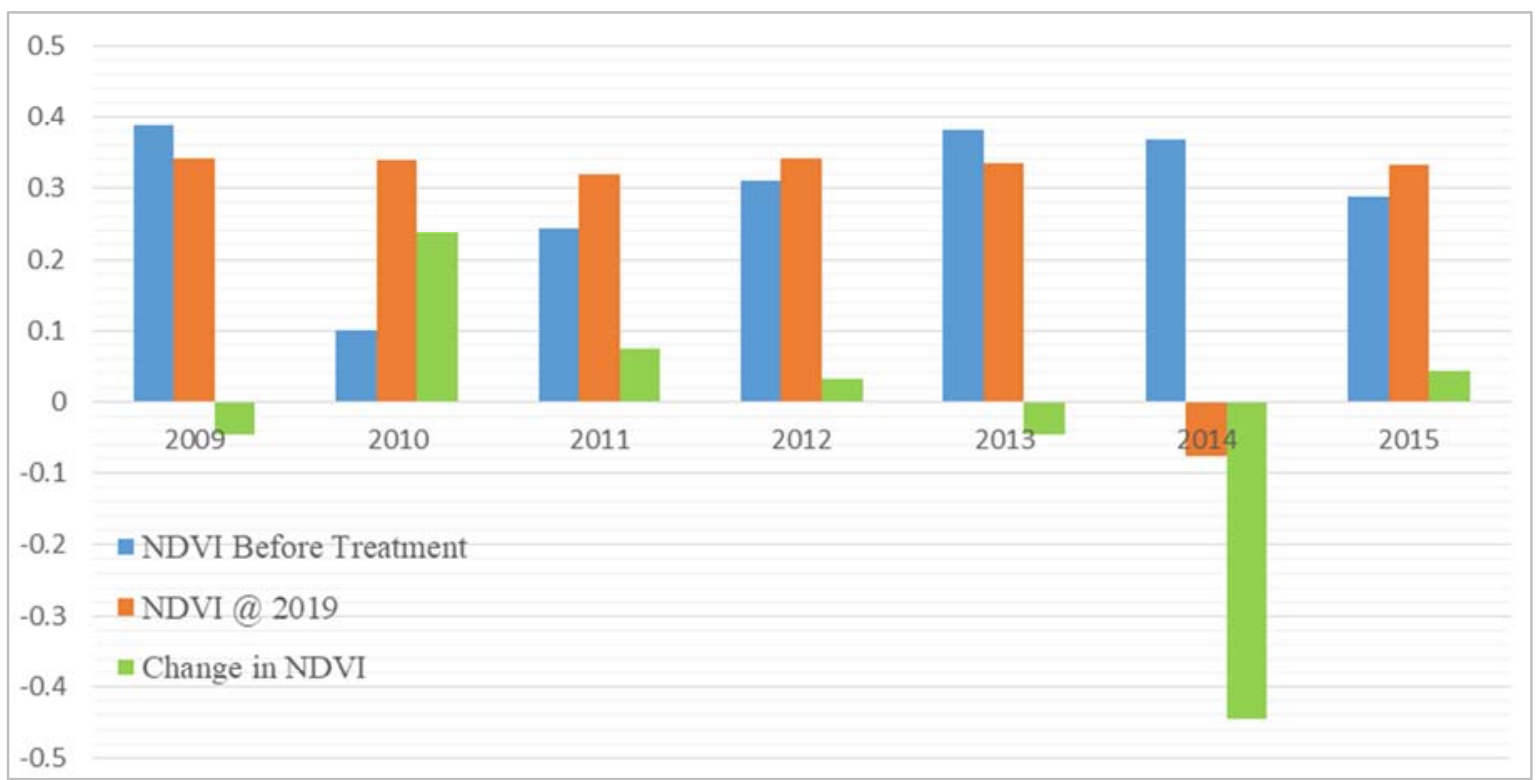

Figure 14. Relative status of treated farms.

\section{Conclusion}

Based on the formulated objectives, the methodology employed, data collected and the analysis made, it can be concluded that 262.89 hectares representing 95.29 percent of the disease under the $2^{\text {nd }}$ CWS phenomenally disappeared during the $3^{\text {rd }} \mathrm{CWS}$ leaving a small margin of 12.99 hectares representing 4.71 percent of the entire $2^{\text {nd }}$ CWS outbreaks. The disappearance of the disease could best be attributed largely to the effective treatment. However, the possibility of natural death by Cocoa trees that were not treated for various reasons cannot be ruled out. Moreover, from the mapped treated areas, it can be concluded that treatment was carried out throughout the entire study area, however, only 45.19 percent of the CSSVD farms were treated. Further, it was established that the majority of the farms treated for the disease during the $2^{\text {nd }} \mathrm{CWS}$ prevailed were performing well. This gives cause to applaud COCOBOD's measure in the treatment of the disease since it is the only means or initiative to sustain the cocoa industry at least for now. Generally, it can be concluded that the treatment of the disease was by and largely effective, and the status of the farms emanated from the treatment very good hence COCOBOD achieving its aim of controlling the CSSVD. 
The period of the CWS should be reduced from five to three years so that newly discovered CSSVD could be promptly and swiftly treated to avert spread due to its contagious nature. Again, cocoa farmers should be trained to be able to identify the disease themselves so that in the event of an outbreak they will readily inform CHED officials for prompt control. Also, farms found to be infected with the disease during surveys should be subjected to critical and proper scrutiny by teams of experts to verify the authenticity of the claim before treatment is done to avoid cutting down incident-free trees. Further, it is recommended that there should be legislation by the parliament of the Ghana Cocoa Board to avert farmer opposition to the treatment of the disease to help minimize the spread of the disease due to its contagious nature. GIS and RS applications are employed in identifying the CSSVD and also determining the VHI of cocoa farms for swift disease control rather than resorting to manual surveys which tend to delay the process thereby encouraging spread. Moreover, COCOBOD should use drones to capture cocoa field data for verification purposes than resort to the services or engagement of Technical Assistants in data acquisition where there could be the tendency of oversight and delays. The research method serves as a guideline for other related studies in an attempt to investigate, quantify and project CSSVD.

\section{Author Contributions}

Fred Oduro Sarpong designed the concept of the manuscript supervised by Jonathan Arthur Quaye-Ballard, and Ernest Biney contributed to the writing of the manuscript.

\section{Declaration of Competing Interest}

All the authors do not have any possible conflicts of interest.

\section{References}

[1] Domfeh, O. et al. (2011) 'Cocoa swollen shoot virus disease situation in Ghana: A review of current trends', African Journal of Agricultural Research. doi: 10.5897/AJAR11.607.

[2] Baah, F. and Anchirinah, V. (2011) 'A review of Cocoa Research Institute of Ghana extension activities and the management of cocoa pests and diseases in Ghana', American Journal of Social and Management Sciences. doi: 10.5251/ajsms.2011.2.1.196.201.

[3] Dzahini-Obiatey, H., Ameyaw, G. A. and Ollennu, L. A. (2006) 'Control of cocoa swollen shoot disease by eradicating infected trees in Ghana: A survey of treated and replanted areas', Crop Protection. doi: 10.1016/j.cropro.2005.09.004.

[4] Andres, C. et al. (2017) 'Combatting Cocoa Swollen Shoot Virus Disease: What do we know?' Crop Protection. doi: 10.1016/j.cropro.2017.03.010.
[5] Ameyaw, G. A., Dzahini-Obiatey, H. K. and Domfeh, O. (2014) 'Perspectives on cocoa swollen shoot virus disease (CSSVD) management in Ghana', Crop Protection. doi: 10.1016/j.cropro.2014.07.001.

[6] Board, G. C. (2018). Manual for cocoa extension in Ghana.

[7] Quainoo, A. (2010) 'PCR-based quarantine procedure for the detection of cocoa swollen shoot virus', Agriculture and Biology Journal of North America. doi: 10.5251/abjna.2010.1.6.1357.1364.

[8] Xiao Hua, X., Xin-Fa, X., Sheng, L., Sha Sha, F., \& Gaowei, W. (2011). Soil Erosion Environmental Analysis of the Three Gorges Reservoir Area Based on the "3S" Technology. Procedia Environmental Sciences, 10, 2218-2225.

[9] Fan, L. X., WU, E. Q., QU, X. C., Chao, L. I. U., NING, B. A., \& Ying, L. I. U. (2016). Distribution characteristics of Spermophilus dauricus in Manchuria City in China in 2015 through '3S'technology. Biomedical and Environmental Sciences, 29 (8), 603-608.

[10] Huang, J., Li, F., Zeng, G., Liu, W., Huang, X., Xiao, Z., Wu, H., $\mathrm{Gu}$, Y., Li, X., \& He, X. (2016). Integrating hierarchical bioavailability and population distribution into potential eco-risk assessment of heavy metals in road dust: A case study in Xiandao District, Changsha city, China. Science of the Total Environment, 541, 969-976.

[11] Lyu, H.-M., Wang, G.-F., Cheng, W.-C., \& Shen, S.-L. (2017). Tornado hazards on June 23 in Jiangsu Province, China: preliminary investigation and analysis. Natural Hazards, 85 (1), 597-604.

[12] Lv, Z., Li, X., Wang, W., Zhang, B., Hu, J., \& Feng, S. (2018). Government affairs service platform for smart city. Future Generation Computer Systems, 81, 443-451.

[13] Biney, E., and Boakye, E., (2021). Urban sprawl and its impact on land use land cover dynamics of Sekondi-Takoradi metropolitan assembly, Ghana. Environmental Challenges, 100168. https://doi.org/10.1016/j.envc.2021.100168.

[14] National population census report 2010. Ghana statistical service,

http://www.statsghana.gov.gh/docfiles/2010_District_Report// Ashanti/OFFINSO\%2520MUNICIPAL. - $\quad$ (Accessed 19/01/2019).

[15] MOFA., 2018. Ministry of Food and Agriculture-Ghana. (Accessed 09/12/2019).

[16] Dzahini-Obiatey, H., Domfeh, O. and Amoah, F. M. (2010) 'Over seventy years of a viral disease of cocoa in Ghana: From researchers' perspective', African Journal of Agricultural Research. doi: 10.5897/AJAR09.625.

[17] Gandhi, G. M. et al. (2015) 'Ndvi: Vegetation Change Detection Using Remote Sensing and Gis - A Case Study of Vellore District', in Procedia Computer Science. doi: 10.1016/j.procs.2015.07.415.

[18] Chingandu, N. et al. (2017) 'The proposed new species, cacao red vein virus, and three previously recognized badnavirus species are associated with cacao swollen shoot disease', Virology Journal. doi: 10.1186/s12985-017-0866-6. 